\title{
Big Five Personality Traits on Academic Performance Among Foundation Students
}

\begin{tabular}{ll} 
& $\begin{array}{l}\text { Kamilah Seman }{ }^{1} \text { \& Zurina Ismail } \\
\text { 1\&2Universiti Tenaga Nasional, Malaysia }\end{array}$ \\
\hline \hline ARTICLE INFO & ABSTRACT \\
\hline \hline Article history: & $\begin{array}{l}\text { There is a significant relationship between personality and academic } \\
\text { achievement. It shows that personality plays an important part in } \\
\text { student academic performance. The main purpose of this study is to } \\
\text { explore the relationship between Big Five Personality traits and } \\
\text { Revised: June 27, 2019 } \\
\text { Accepted: September 5,2019 }\end{array} \quad \begin{array}{l}\text { academic performance among foundation student based on their } \\
\text { CGPA. There were 137-foundation students from private universities }\end{array}$ \\
\hline Keywords: & $\begin{array}{l}\text { in Malaysia participants in this study. With 92 female and 45 males } \\
\text { involved. Pearson correlation analysis was performing in this study. } \\
\text { Big Five Personality, } \\
\text { Academic Achievement, } \\
\text { Academic Performance } \\
\text { relationship between personality and academic performance. In } \\
\text { details, Agreeableness, Conscientiousness, and Openness were } \\
\text { positively significant related to CGPA, while Extraversion and } \\
\text { Neuroticism were negatively related to the CGPA. This result supports } \\
\text { the other findings. With this finding, the academician will have more } \\
\text { understanding on their students. There are a number of factors that } \\
\text { influence students' academic achievement and one of its personality } \\
\text { factors. Besides that, this result also can give useful information to the } \\
\text { lecturer in order to understand student's personality and to match their } \\
\text { teaching styles with the student's personality to improve the student's } \\
\text { performance. }\end{array}$ \\
None &
\end{tabular}

Corresponding Author: Kamilah Seman, Universiti Tenaga Nasional: skamilah@uniten.edu.my

(C) Kamilah Seman \& Zurina Ismail

This is an open access article under the CC BY-SA 4.0 international license.

\section{Introduction}

Education is one of the important elements need to be equipped by individual in this challenging world. One of the main problems in educational sector is culture studies and students' behavioral issues. Academic achievement becomes important issues. Most of the researcher is searching factor that influence academic performance.

In align with the global needs of the higher education; Malaysia has a vision to become a prestige educational hub in ASEAN. Many researchers found that personality can affect the individuals' behavior and will influence the performance. However, so little research applies the concept personality in foundation student's academic performance.

This study will focus on foundation students because of several reasons. One of the reasons is foundation students they just had finished their secondary school education. As they entered as first year freshmen, they need to adapt with new teaching and learning process. There is a different in learning strategy between secondary school and tertiary level.

According to Ibrahim et al. (2014), social, economic and political of a country will be influenced by the high quality of education in the country. Authors also stated that the student's self-esteem development was quite worrying because most of them are so passive and cannot communicate well after they graduate.

Therefore, it is crucial for researchers to investigate the factors that can influence student performance. Matthews et al., (2005) revealed that personality plays an important role in academic performance. Besides that, there are several researchers study about the personality and academic performance found that personality traits and academic performance was strongly correlated (Conrad and Patry, 2012; Feyter et al., 2012; Premuzic and Furnham, 2003; Hakimi et al., 2011). 
Most of the studies conducted by researchers stated that the Big Five Personality traits influencing students' academic performance (Conrad and Patry, 2012; Feyter et al., 2012; Premuzic and Furnham, 2003; Geramian et al., 2012; Paunonen, 2001; Laidra et al., 2007; Lounsbury et al., 2003). However, most of the studies were conducted in other countries and for the different students. Because of that, this study will study the influence of Big Five Personality traits on academic performance of Foundation students in private universities in Malaysia.

The turnover rate among drop students will be reduced by understanding the influence of Big Five Personality and student performance. The academician can be more effective in engaging their student in classroom by applying teaching skills that will appropriate with the students' personality. Based on these explanations, the study will focus to analyze the influence of Big Five Personality on academic performance.

Big Five Personality

Big Five Personality Model is the dominant conceptualization of personality structure that consists of Neurioticism/ Emotional Stability, Extraversion, Openness to Experience, Agreeableness, and Conscientiousness (McCrae and Costa, 1997). In addition, Mohammed, et al. (2009) stated that there has been increasing interest among researchers to study Big Five Personality Factor Model. Most of the previous researcher has been investigate the big five traits with job performance and academic achievement (Ozer and Benet-Martinez, 2005).

Big Five Personality traits or also known as Five Factor Model that been most agreed as personality model. According to Petska (2006), Five Factor Model (FFM) consists of Neuroticism, Extraversion, Openness, Agreeableness, and Conscientiousness. Author define neuroticism (emotional stability) people are calm and not easily upset or frustrated, they can control the emotional well. While extraversion people will have this kind of criteria such as talkative, energetic and assertive, they are people whom open-minded. Next is agreeableness people, who are cooperative and trustful with their good-natured. While openness people who have active imagination, they would like to have preference in variety and they will follow their inner feelings. Lastly, conscientiousness people are more responsible, dependable and work with orderly manner or systematically.

Meanwhile, based on Smith (2003), extraverts prefer to involve with others and activities. Openness refers to the people who like to produce new ideas and they normally like new experiences. Other than that, conscientiousness refers to the person who is tends to affect motivation at work. Author also stated that neuroticism people are more cool and calm.

Neuroticism

Neuroticism can be described as emotional, nervous, easily tensed and anxious with all negative emotionality. Some characteristic that formed from neuroticism include irrational perfectionistic beliefs low self-esteem and pessimistic attitudes. Based on study by Ahmad and Rana (2012), they discuss on reverse relationship between Neuroticism and emotional intelligence which explained the lower Neuroticism will lead to higher the emotional intelligence. Refer to Feyter et al., (2012), identify there is a negative effect of neuroticism on academic achievement. This support Zhang (2003) findings that neuroticism has a negative significant relationship with academic performance. Most of the researcher has identified Neuroticism as hinders predictor in academic achievement. However, Neuroticism and academic achievement relationship might be more complex because of mixed and inconclusive results (Feyteret.al, 2012).

Extraversion

Those individual that have a confidence to experience new place is extraverted category (De Young, et. al., 2005). Zhang (2006) stated extraverted person is someone has much interested in people and help other than for personal use. Heinstrom (2000) identified a few extraverts' characteristic such as physically active, talkative where is different with introvert person who prefer to be alone, reserved and independent.

According to Furnhamet. al. (1999), conclude that extraverted individuals will learn better when they are work in group rather than work alone. While, Komarrajuet. al. (2009) found that sociability as an aspect of the extraverted personality has an important influence on academic achievement.

Extroverts focus their attention and gain energy through interaction with the external world of people, activities and things; while introverts focus their attention and gain energy through the inner world of ideas, impressions, and emotions. Introverts may prefer written communication while extroverts may prefer to communicate using discussion and interaction (Russo and Kaynama, 2012).

Openness to Experience

Intellect also known as openness to experience is the factor of Five Factor Model (FFM). Openness to experience relates with individual need for diversity, affective, behavioral tendencies and intellectual interest. The characteristic for openness to experience is receptive to new ideas, broad-minded, and being imaginative. According to Zhao and Seibert (2006), openness to experience is important for entrepreneurs as they need to explore new ideas and take innovative approaches to the development of products and the organization of businesses. There is a significant positive correlation between openness to experience with student's 
knowledge and academic achievement (Sallehet. al., 2010). This study support O'Connor and Paunonen (2007) finding, openness to experience was sometimes positively correlate with student's achievement.

Agreeableness

Agreeableness can be defined as an individuals shared orientation toward others people. Some characteristic adaptations of agreeableness includes trait such as trust, sincerity, a forgiving attitude, belief in cooperation, and a potential reputation as a pushover (Petska, 2006). Komarraju, et. al. (2011) had discussed on learning styles and personality is linked together and plays important roles in influencing academic performance. This statement support study by MhamedTaher (2011) that identified agreeableness, conscientiousness, and openness to experience had a positive relationship with students' performance. The other personality traits such as extraversion and neuroticism are proved to predict a negative relationship upon students' performance.

\section{Conscientiousness}

Petska (2006), describes Conscientiousness as goal-directed behavior, following rules and norm, thinking before acting and prioritizing task. The character for Conscientiousness can be identified as competence, dutifulness, self-discipline, order, and deliberation. O'Connor and Paunonen (2007), in their research, identified among the five-factor model only Conscientiousness has been correlate with academic performance. Refer to a study conducted by Sallehet. al., (2010) about the effectiveness of pair programming and conscientiousness factor, they identified conscientiousness the most consistent predictor of academic performance. Meanwhile Conrad and Patry (2012) found that there is a strong positive relationship between conscientiousness and academic performance as measured by final grades. Whereas Feyteret. al. (2012) also found that conscientiousness positively affected academic performance indirectly through academic motivation.

\section{Big Five Personality and Academic Performance}

Academic performance has been successfully predicted among youth by using the big five personality traits (Lounsbury et. Al., 2003). Based on the study conducted by Nyarko et al. (2016), only Conscientiousness was significantly influence student's academic performance. Authors stated that students will achieve better result or performance if they organize their plan and activities properly. Besides that, the other study conducted by Geramian et al. (2012) also reveal that only two items were highly significant which are Conscientiousness and Openness to Experience. The authors define personality is the differences of how people talk, thinks, feels, and behave. Difference people have different personality.

According to the study conducted by (O'Connor and Paunonen, 2007; Koning et al., 2012), authors found that Conscientiousness has a strong positive relationship with the student's GPA or students' performance. Student's performance in Macroeconomics or Microeconomics subject can be increased by matching the student's personality traits with the course content and structure (Bisping and Eells, 2006).

Russo and Kaynama (2012) also do the study in personality traits and academic achievement and authors revealed that female students will perform better if they have feeling and judging personality types. Authors clearly stated that academic performance of each students will differ depends on their personality types. In line with this study, Hakimi et al. (2011) also found that personality traits were significantly related to academic achievement. Based on this study, big five personality were significantly related to academic performance. Only three variables which are agreeableness, conscientiousness, and openness have a positive relationship with academic performance, while the other two variables which are neuroticism and extraversion has a negative relationship with academic performance.

Big Five Traits have been link to the various behaviors such as academic performance and job performance (Ozer and Benet-Martinez, 2006). According to McCrae and John (1992), experiences which describes intellectual or creative interest refers to openness. Meanwhile, conscientiousness was related to the person's achievement. If the people have high on conscientiousness, they tend to be hardworking and able to complete tasks properly. But, if the person was an irresponsible, impulsive, and disordered, the person has a low conscientiousness.

Academic performance can be improved by understanding the factors which affect academic motivation. Hazrati-Viari, et al. (2011) found that the most important predictor of intrinsic motivation was conscientiousness. Authors also revealed that academic motivation was mediate the relationship between openness to experience and conscientiousness with academic performance. Eyong et al. (2014) also investigated the influence of personality traits on academic achievement of secondary school. Authors found that high conscientious students performed better than lower conscientiousness students. Besides that, students who are highly agreeable performed significantly better than low agreeable students. Students with highly neuroticism performed significantly worse than the lower neuroticism student. 


\section{Research Methodology}

This research was conducted through quantitative analysis. Quantitative analysis means that this study was conducted by distributing set of questionnaires to the respondents in order to get the data. In this study, the questionnaire was measured by using Likert scale. The respondents for this study are from Foundation students at Private University in Malaysia which consist of Universiti Tenaga Nasional, Universiti Teknology Petronas, and Universiti Multimedia. Sample was selected convenience sampling. Convenience sampling is a nonprobability sampling technique where subjects are selected because of their convenient accessibility and proximity to the researcher. These methods of data collection was used because it is cheaper, more convenient and gave access to people who were willing and ready to participate in the study. Foundation students were selected because Foundation was the earliest stage in higher education. This study can help to identify the personality of the students earlier. The questionnaire was sent to the 150 respondents. But only 137 questionnaires were returnable.

The questionnaire consists of two sections, which are:

Section A: Demographic Profile

Under demographic profile, consist of gender, race, age and CGPA

Section B: Big Five Personality Traits

Under section B consist of two dimensions that are Big Five Personality Traits and academic performance. Big five personality consist of 44 items based on Big Five Inventory (BFI), (John, 1991). While academic performance is measured based on their CGPA.

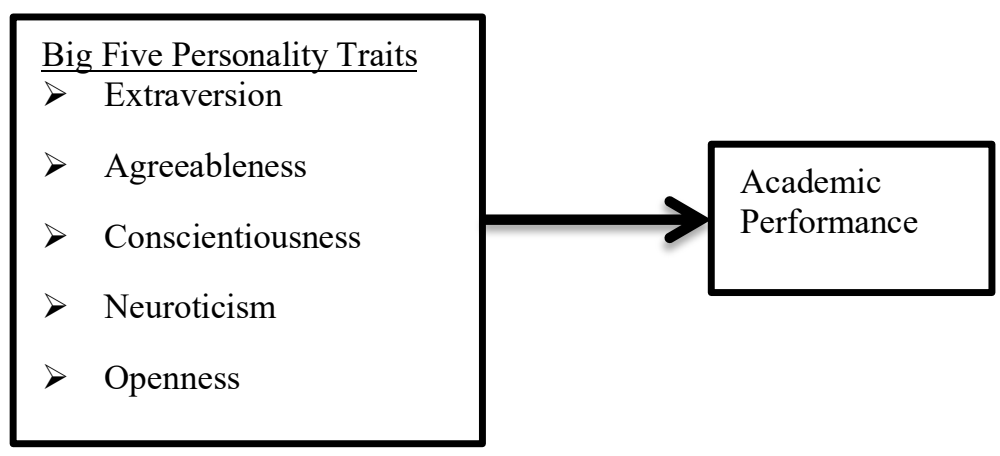

Figure 1. Research Framework

Big Five Inventory (BFI) (John, 1991) which includes 44 items was used to measure the personality traits of the students. The BFI was used because it is easy for respondents to understand each of the questions or items under BFI. Academic performance was measured by cumulative grade-point average (CGPA) achieve by the students (Duff, et. al., 2004). Students reported their CGPA from their last semester.

A survey questionnaire was developed to gather data required to measure the influence of Big Five Personality traits on academic performance among students at Private University in Malaysia. The questionnaire uses 7point Likert scale from Strongly Agree $(=1)$ to Strongly Disagree $(=7)$. Likert scale was used in this study because according to Clifford (1985), Likert scale was easy to analyse and understand. It also will cut cost and time to answer the questionnaire.

The survey questionnaire consists of three sections. Section A is about the respondent's demographic which includes gender, age, race, and CGPA. Section B is to measure the Big Five Personality traits by using Big Five Inventory (BFI) (John, 1991). Statistical Package for Social Science (SPSS version 24.0) will be used to convert raw data collected into meaningful information.

Data source for this research was obtained from both primary and secondary source. Primary data are available through observation and questionnaire, while secondary data through previous research and web information. Primary data was obtained from questionnaire by provide structured question method with close ended question type by using Likert scale. The secondary data use literature, journal, magazine, article and internet in making existing theoretical basic as additional information to support primary data in this research. 


\section{Discussion and Recommendation}

Gender and Race

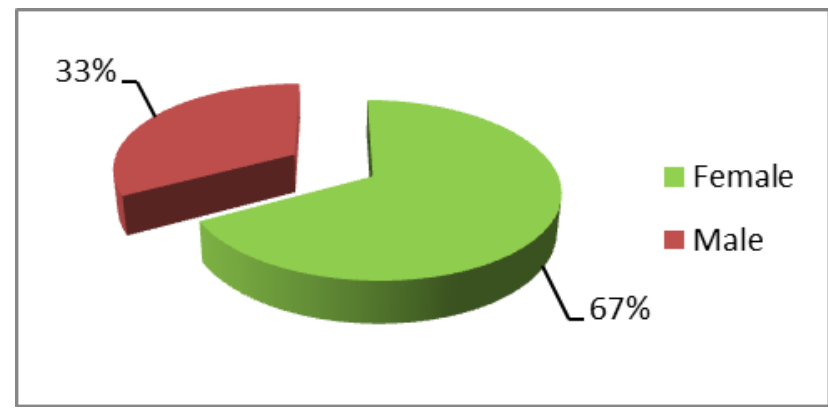

Figure 2. Gender

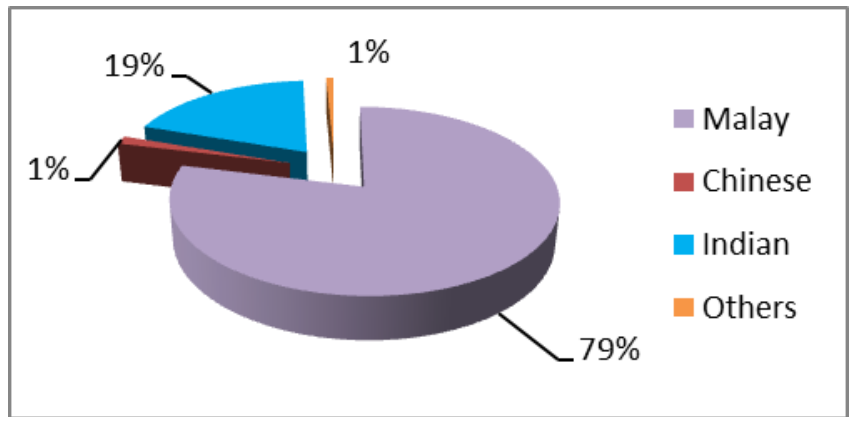

Figure 3. Race

Majority of the respondents is Malay which represents 108 students $(78 \%)$, followed by Indian, 26 students (15\%), and by Chinese, 2 students (1\%), and lastly by others, 1 student (1\%).

$C G P A$

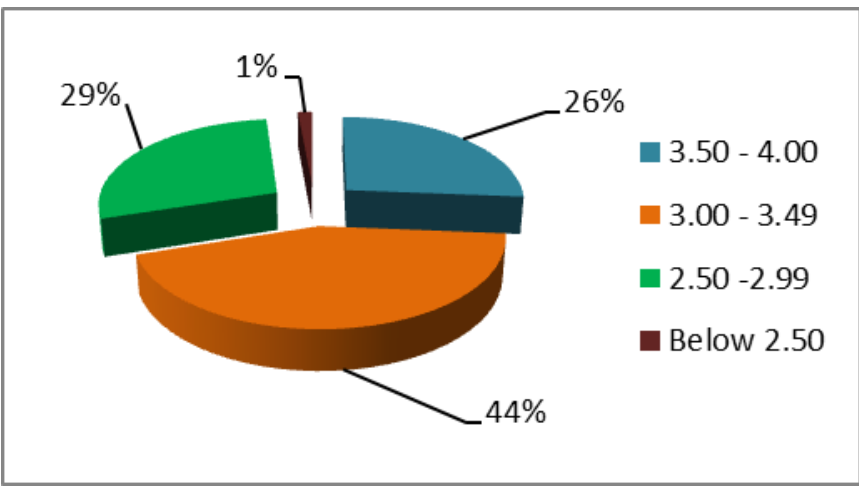

Figure 4: CGPA

Most of the respondent for this study consists of students who achieve CGPA of 3.00-3.49 which is $44 \%$ (60 students) of the respondents. Then, it would follow by students who got $2.50-2.99$ (29\%) which represent 39 students. There are $26 \%$ (36 students) who got $3.50-4.00$ and $1 \%$ ( 2 students) who got below 2.50 . This result shows that most of the students quite excellent in their study. 
Besides that, majority of them have openness personality which represents $40 \%$ of the respondents. Then, it followed by $19 \%$ respondents for extraversion personality, then $17 \%$ for neuroticism, and followed by agreeableness and conscientiousness respectively.

e.g:

\section{Cronbach's Alpha Coefficient}

Table 1 show that the Cronbach's alpha coefficient for extraversion is 0.708 , agreeableness is 0.716 , conscientiousness is 0.734 , neuroticism is 0.772 , and openness is 0.833 , which is considered acceptable.

Table 1. Cronbach's Alpha

\begin{tabular}{lll}
\hline Items & Cronbach's Alpha & N of items \\
\hline Extraversion & 0.708 & 8 \\
\hline Agreeableness & 0.716 & 9 \\
\hline Conscientiousness & 0.734 & 9 \\
\hline Neuroticism & 0.772 & 8 \\
\hline Openness & 0.833 & 10 \\
\hline
\end{tabular}

Pearson Correlation

Table 2. Cronbach's Alpha

\begin{tabular}{lllllll}
\hline & & $\mathrm{E}$ & $\mathrm{A}$ & $\mathrm{C}$ & $\mathrm{N}$ & $\mathrm{O}$ \\
$\mathrm{CGPA}$ & $\begin{array}{l}\text { Pearson } \\
\text { Correlation }\end{array}$ & $-.130^{* *}$ & $.159^{* *}$ & $.390^{* *}$ & $-.140^{* *}$ & $.210^{* *}$ \\
$\begin{array}{l}\text { Sig. } \\
\text { tailed) }\end{array}$ & $(2-$ & .000 & .009 & .000 & .000 & .000 \\
$\mathrm{~N}$ & 137 & 137 & 137 & 137 & 137 \\
\hline
\end{tabular}

Refer to the table above, Agreeableness showed low positive significant relationship with $0.159 * *(\mathrm{p}<0.000)$. This result was supported by Komarraju, et al. (2011) which is stated that Agreeableness was positively correlated with GPA.

Conscientiousness showed moderate positive significant relationship with $0.390 * *(\mathrm{p}<0.000)$. This result was supported by Hakimi, et al. (2011), which revealed that conscientiousness was the most important predictor of academic performance.

Openness traits showed low positive significant relationship with $0.210 * *(\mathrm{p}<0.00)$. This result was supported by Paunonen and Ashton (2001), which is the authors, reported that the relationship between openness and academic achievement was positive but has weak relationships.

Two traits showed inversely significant relationship. Extraversion showed low negative significant relationship with $-0.130 * *(p<0.00)$, while Neuroticism showed low negative significant relationship with $-0.140 * *(p<$ 0.00). This finding was supported by Mhamed Taher (2011) that shows Extraversion and Neuroticism have a negative correlation with academic performance.

Based on this study, there is a significant relationship between all the variables under Big Five Personality and academic performance (CGPA). Extraversion and Neuroticism were negatively related to the CGPA while Agreeableness, Conscientiousness, and Openness were positively related to CGPA. This result was supported by Soraya Hakimi et al.(2011).

The study revealed academic performance was found significantly correlate with big five personality model. But the result was not so strong. For future research we should suggest to study with moderator effects. There is a lot of factor that contributes to academic performance such as factor of intelligence (Poropat, et. Al., 2009). Researcher should applying moderator effects to enhance the students' academic performance. This is because of the relationship between personality and academic performance is complexity and subtle, the researcher need have further exploration. 


\section{Conclusion}

Results from pearson correlation analysis shows that extraversion and academic performance was negative. Extroverted people tend to be more talkative, spontaneous, like to solve problem on their on way, thus it will lead to the lower academic performance because they might not focus in the classroom. This finding was supported by Nayak (2016). Neuroticism and academic performance also shows negative relationship. It is because neuroticism people normally tend to be more anxious and doubt. So it will affect the academic performance of the students.

This result was supported by Hakimi et al. (2011). Result of this study also shows that agreeableness, conscientiousness, and openness were positively related to CGPA. This is because normally agreeableness people are more cooperative, good-natured and trustful and this will help the students to get better performance. Besides that, conscientiousness people are more responsible person, while opennes person have active imagination which will help the students to study properly (Petska, 2006). It means that if the student's personality was high in terms of agreeableness, conscientiousness and openness, their performance will increase, but if their personality was high in terms of extraversion and neuroticism, it will lower their performance. This result was supported by Hakimi et al. (2011).

Its important to the practitioner such as lecturers and educators should understand and know about their student's personality in order to matching the personality with the teaching skills. This will help to increase student's performance and automatically will give greater impact to the social, economic and politic system in Malaysia.

\section{References}

Ahmad, I. \&Rana, S. (2012). Affectivity, Achievement Motivation, and Academic Performance in College Students. Pakistan Journal of Psychological Research, Vol. 27, No. 1, pp. 107-120.

Bisping, T. O. \&Eells, J. B. (2006). Personality Type as a Determinant of Student Performance in Introductory Economics: Macroeconomics vs. Microeconomics. Journal of Economics and Economic Education Research, Vol. 7, No. 1.

Conrad, N. \&Patry, M. W. (2012). Conscientiousness and Academic Performance: A Mediation Analysis. International Journal for the Scholarship of Teaching and Learning, Vol. 6, No. 1.

Costa, P. T. \& McCrea, R. R. (1995). Domain and Facets: Hierarchical Personality Assessment Using the Revised NEO Personality Inventory. Journal of Personality Assessment, Vol. 64, pp. 21-50.

Eyong et al. (2014). The Influence of Personality Trait on the Academic Performance of Secondary School Students in Cross River State, Nigeria. Journal of Humanities and Social Science, Vol 19, Issue 3, pp 12-19.

Feyter, T. D. et al (2012). Unraveling the Impact of the Big Five Personality Traits on Academic Performance: The Moderating and Mediating Effects of Self efficacy and Academic Motivation. Center for Business Management Research, Hogeschool-UniversiteitBrussel, K.U.Leuven Association, Belgium.

Geramian, S. M. et al (2012). The Relationship between Personality Traits of International Students and Academic Achievement. Social and Behavioral Sciences, Vol 46, pp. 4371-4379.

Fleming, N. D. \& Mills, C. (1992). Not Another Inventory, Rather a Catalyst for Reflection. Professional and Organizational Development Network in Higher Education.

Fleming, N. D. (1995). I'm Different; not Dumb. Modes of Presentation (V.A.R.K) in the Tertiary Classroom. Research and Development in Higher Education, Vol. 18, pp. 308-313.

Furnham, A. et. al. (1999).Personality, Learning Style and Work Performance. Personality and Individual Differences, Vol. 27, pp. 1113-1122.

Hazrati-Viari, et. al. (2011). The Effect of Personality Traits on Academic Performance: The Mediating Role of Academic Motivation. Social and Behavioral Sciences, Vol. 32, pp. 367-371.

Ibrahim, N. S. et al. (2014). A Meta-Analysis of the Relationship Between Big Five Personality Traits and Students' Academic Achievement. Journal of Social Science Research, Vol. 2

John, O. P., Donahue, E. M., \&Kentle, R. L. (1991).The Big Five Inventory - Versions 4a and 54. Berkeley, CA: University of California, Berkeley, Institute of Personality and Social Research.

Komarraju, M. \&Karau, S. J. (2005).The Relationship between the Big Five Personality Traits and Academic Motivation.Personality and Individual Differences, Vol. 39, pp. 557-567.

Komarraju, M., Karau, S. J. \&Schmeck, R. R. (2009).Role of the Big Five Personality Traits in Predicting College Students' Academic Motivation and Achievement. Learning and Individual Differences, Vol. 19, pp. 47-52.

Laidra, K., Pullmann, H. \&Allik, J. (2007). Personality and Intelligence as Predictors of Academic Achievement: A Cross-Sectional Study from Elementary to Secondary School. Personality and Individual Differences, Vol. 42, pp. 441-451. 
Lounsbury, J. W. et al. (2003). Broad Versus Narrow Personality Traits in Predicting Academic Performance of Adolescents. Learning and Individual Differences, Vol. 14, pp. 67-77.

McCrae, R. R. \& John, O. P. (1992).An Introduction to the Five-Factor Model and Its Applications.

Nyarko, K. et al. (2016).The Influence of the Big Five Personality and Motivation on Academic Achievement among University Students in Ghana. British Journal of Education, Society \& Behavioural Science, Vol 13, pp. 1-7.

Ozer D. J. \& Martinez, V. B. (2006). Personality and the Prediction of Consequential Outcomes. Annual Review of Psychology, Vol 57, pp. 401-421.

Paunonen, V. P. (2001). Big Five Factors and facets and the Prediction of Behavior. Journal of Personality and Social Psychology, Vol. 81, No. 3, pp. 524-539.

Petska, et. al. (2006).Using Personality Variables to Predict Academic Success in Personalized Systems of Instruction. College of Education and Human Sciences.

Premuzic, T. C. \& Furnham, A. (2009). Mainly Openness: The Relationship between the Big Five Personality Traits and Learning Approaches. Learning and Individual Differences, Vol. 19, pp. 524-529.

Premuzic, T. C. \&Furnham, A. (2003). Personality Predicts Academic Performance: Evidence from two Longitudinal University samples.

Poropat, A.E. (2009). A meta-analysis of the five-factor model of personality and academic performance. Psychological bulletin, 135(2), 322.

Russo, C. J. and Kaynama, S. (2012). The Impact of Personality Type and Gender on Student' Performance in a Business Capstone Course. Academy of Educational Leadership Journal, Vol. 16, No. 1.

Soraya Hakimi et al. (2011). The Relationship between Personality Traits and Academic Achievement. Social and Behavioral Sciences, pp. 836-845. 